OPEN ACCESS

Edited by:

Julie Messier,

University of Waterloo, Canada

Reviewed by:

Henrik Andren,

Swedish University of Agricultural

Sciences, Sweden

Guillem Chust,

Centro Tecnológico Experto en

Innovación Marina y Alimentaria (AZTI), Spain

*Correspondence:

Yaron Ziv

yziv@bgu.ac.ll

Goggy Davidowitz

goggy@email.arizona.edu

tThese authors have contributed equally to this work

Specialty section:

This article was submitted to Biogeography and Macroecology,

a section of the journal

Frontiers in Ecology and Evolution

Received: 29 August 2018 Accepted: 05 April 2019

Published: 24 April 2019

Citation:

Ziv Y and Davidowitz G (2019) When

Landscape Ecology Meets

Physiology: Effects of Habitat

Fragmentation on Resource Allocation Trade-Offs. Front. Ecol. Evol. 7:137. doi: 10.3389/fevo.2019.00137

\section{When Landscape Ecology Meets Physiology: Effects of Habitat Fragmentation on Resource Allocation Trade-Offs}

\author{
Yaron Ziv ${ }^{1 * t}$ and Goggy Davidowitz ${ }^{2 \star t}$ \\ ${ }^{1}$ Spatial Ecology Lab, Department of Life Sciences, Ben Gurion University of the Negev, Beer-Sheva, Israel, ${ }^{2}$ Department of \\ Entomology, University of Arizona, Tucson, AZ, United States
}

Landscape heterogeneity is a general feature of natural environments, strongly affected by habitat fragmentation. It can affect a population's dynamics and probability of extinction. Fragmentation increases among-patch isolation and decreases patch size, resulting in a reduction in available resources in smaller patches. To persist, animals must be able to translate the variation imposed by fragmentation into adaptive energy allocation strategies that enable populations to avoid extinction. This means that physiological adaptations are expected to reflect changes in landscape configuration, especially in the size of the natural habitat patches and degree of isolation among them. We propose a novel, integrative conceptual framework in which spatial characteristics of the environment, imposed by fragmentation, lead to specific life-history traits that increase survival (at the individual level) and decrease the likelihood of extinction (as an emergent property at the population level). We predict that a resource allocation trade-off between the life-history traits of reproduction and dispersal along a fragmentation gradient will emerge. Populations occurring in patches of different sizes and isolations along gradients of fragmentation and productivity will exhibit differences in the strength of the dispersal-reproduction trade-off. Emerging from this framework are several explicit and testable hypotheses that predict that the dispersal-reproduction trade-off will be shaped by landscape heterogeneity imposed by fragmentation. Hence, this trade-off serves as the mechanistic link that translates environmental variation created by fragmentation into variation in species abundances and population dynamics by lowering local extinction probability and increasing overall population persistence.

\begin{abstract}
Keywords: landscape ecology, habitat fragmentation, resource allocation tradeoff, dispersal-reproduction tradeoff, landscape physiology, productivity gradient, fragmentation gradient
\end{abstract}

\section{INTRODUCTION}

Here, we develop a framework that integrates two disparate fields of study, landscape ecology and evolutionary physiology; promoting an emerging new field, landscape physiology. Landscape ecology relies on correlations among landscape and population/community parameters but usually ignores individual-level mechanisms. Evolutionary and ecological physiology, in contrast, are mechanistic disciplines that focus on the microhabitat and often ignore landscape-level processes. 
This framework generates explicit and testable hypotheses of how an organism translates habitat characteristics resulting from fragmentation per se (the condition of reduced patch size and greater isolation among patches), through the physiological mechanism of resource allocation strategies, into population dynamic parameters of reproduction, survival, and abundance. Integrating across physiology and the landscape in one unified framework will extend our ability to understand population extinction and persistence in light of current increases in habitat loss and climate change.

Landscape heterogeneity is one of the general features of natural environments. Habitats are distributed in space (hereafter, natural patches), are of different sizes and are at different distances. Natural patches of different size provide individuals with variable abiotic and biotic resources and niche opportunities and therefore may change the fitness of an individual. Different distances between natural patches require different dispersal efforts and may affect the energy and resources devoted to dispersal at the expense of energy and resources devoted to growth and fecundity in a particular natural patch. In the context of this paper, resources refer to nutritional and energy resources such as from carbohydrates, lipids, and proteins.

One form of landscape heterogeneity related to human impact is habitat fragmentation. Habitat fragmentation stresses the linkage between spatial elements and emphasizes the challenges organisms face in evolving strategies of resource allocation to life history traits. In this paper, we focus on the coupling of patch size and isolation in the context of habitat fragmentation, but also consider cases where size and isolation are decoupled to reflect large heterogeneous contexts.

Habitat fragmentation, a dominant feature of many landscapes, can result from habitat loss, due to, among others, road or city construction, and can affect a population's dynamics and probability of extinction (Fahrig, 2002, 2003; Reed, 2004; Hanski et al., 2013). This is especially true in regions where intensive use of agriculture has resulted in extensive fragmentation of natural habitats (Belanger and Grenier, 2002; Green et al., 2005; Millennium Ecosystem Assessment, 2005; Giladi et al., 2011). Climate change may possibly exacerbate the degree of fragmentation of natural habitats (Karieva et al., 1992; Klapwijk and Lewis, 2001; Opdam and Wascher, 2004). Fragmentation has multiple effects, leading to: (i) loss of total habitat area, (ii) reduced average habitat patch size, and (iii) increased distances among patches (the latter two reflect fragmentation per se effects; e.g., Gavish et al., 2012). Intensification of habitat fragmentation may result in a decline in species abundances and diversity, due to the differential withinand among-patch effects of fragmentation. At the withinpatch level, small patch size leads to a reduction of suitable habitat, lower habitat quality and fewer resources, and thus to reduced population sizes and higher probability of extinction (MacArthur and Wilson, 1967). At the among-patch level, increased fragmentation may lead to greater distances among patches (low connectivity) and, possibly, to lower recolonization rates and a lower probability of replacement by individuals of that species from nearby habitats (Brown and Kodric-Brown, 1977; Hanski and Gilpin, 1997; Hanski and Gaggiotto, 2004).
For a population to persist, individuals within the population translate the abiotic and biotic variation they experience, including those imposed by fragmentation, into energy allocation strategies to life history traits. These life history traits in turn, affect demographic parameters that enable the population to avoid extinction. Life-history traits are strongly shaped by natural selection and result in adaptive states that should increase survival and enhance fitness (Roff, 1992; Stearns, 1992). In particular, natural selection acting on physiological priorities of energy allocation will result in tradeoffs in investment of limited energy and resources that maximizes fitness (Stearns, 1989; Zera and Harshman, 2001). A major physiological trade-off is one that involves dispersal and fecundity. We propose that a dispersalreproduction trade-off serves as the physiological, mechanistic link by which organisms translate environmental variability experienced in fragmented habitats into life history traits that result in population persistence within those habitats (Hughes et al., 2003; Aguette and Schtickzelle, 2006; Guerra, 2011; King et al., 2011; Bonte et al., 2012). Here we focus on animals, but similar considerations are applicable to other organisms as well.

Life history evolution is largely concerned with phenotypic traits such as reproduction and survival that directly affect fitness (Roff, 1992; Stearns, 1992). Ecological and evolutionary physiology seeks to understand the mechanisms underlying these phenotypes (Garland and Carter, 1994; Feder et al., 2000; Karasov and Martinez del Rio, 2007). For example, the life history traits of body size and development time are regulated by eight signaling and hormonal pathways in insects (Nijhout et al., 2013; Gokhale and Shingleton, 2015), which result in 40,320 possible permutations of the control of growth (Davidowitz, 2016). This large number of possible combinations can be distilled into three physiological traits (Davidowitz, 2016) that explain $99 \%$ and $93 \%$ of the response of body size and development time, respectively, to simultaneous directional selection (Davidowitz et al., 2016). Thus, we can understand how two life history traits co-evolve, by understanding three underlying physiological mechanisms.

The allocation of resources is of major concern in understanding the physiology underlying life history traits: the strategies that have evolved to allocate resources and energy to one trait over another (Ricklefs and Wikelski, 2002). Such resource allocation strategies underlay constraints and tradeoffs among life history traits (Zera and Harshman, 2001; Boggs, 2009; Flatt and Heyland, 2011) and that of the landscape physiology framework presented here. Specifically, fecundity and dispersal are the life history traits of interest in this framework, whereas the strategies of resource allocation are the physiological mechanism that underlies these traits. Because this framework focuses on resource allocation strategies imposed by landscape fragmentation, it is considered a landscape physiology framework.

In this paper, we posit that spatial characteristics of the environment, imposed by fragmentation, force specific adaptive states of life-history traits to increase survival (at the individual level) and avoid extinction (as an emergent property at the population level). We argue that studies of life-history traits and population dynamics should incorporate spatial characteristics of fragmentation (e.g., landscape configuration and habitat patch 
characteristics) in order to better understand how physiology constrains an individual's allocation strategy. We propose the integration of two distinct fields-landscape ecology and evolutionary physiology —into Landscape Physiology. While the need to integrate these two fields has been previously suggested (Chown et al., 2004; Chown and Gaston, 2008; Bonte et al., 2012; Ellis et al., 2012), the integration of physiology and lifehistory into landscape-level processes is still extremely rare (Ellis et al., 2012). A deep understanding of populations in a fragmented landscape requires knowledge of population and lifehistory parameters that a physiological perspective can provide (Berwaerts et al., 1997; Templeton et al., 2001; Hanfling et al., 2004; Bakker et al., 2010; Willi and Hoffmann, 2012; Hanski et al., 2013). We are still lacking a clear understanding of the physiological mechanisms by which organisms are able to cope with the effects of fragmentation in ways that scale upwards and reduce the probability that populations will be lost.

Below, we first provide background on dispersal-reproduction resource allocation tradeoffs in general. We then present the landscape physiology framework that explains how animals translate habitat heterogeneity due to fragmentation into resource allocation strategies to dispersal and reproduction. Last, we describe three explicit hypotheses that emerge from this framework.

Similar to many other trade-offs, the dispersal-reproduction trade-off emerges because organisms have finite resources to invest in growth, maintenance, survival and reproduction. Allocation of resources to any one of these functions reduces the amount available to the others (de jong, 1993). Such resource allocation decisions directly affect fitness and therefore underlie the evolution of traits in general and life-history traits in particular (Stearns, 1989, 1992; Boggs, 2009). Resource allocation strategies are influenced by the amount of available resources: reduced nutrient availability can significantly magnify a trade-off (increase the slope of the tradeoff), whereas increased nutrient availability can reduce or eliminate a trade-off (decrease the slope of the tradeoff) (Kaitala, 1987; Chippindale et al., 1993; Nijhout and Emlen, 1998; Zera and Harshman, 2001; Harshman and Zera, 2007). Ever-changing physiological priorities throughout ontogeny govern the relative allocation of resources to organismal processes as a function of nutrient input (Zera and Harshman, 2001; Boggs, 2009). For example, under stressful conditions, allocation to storage or maintenance can take precedence over allocation to reproduction (Perrin et al., 1990; Rogowitz, 1996), or resources can be reallocated from existing structures, as in the case of flight muscle histolysis and the subsequent reallocation of these resources to reproduction (Marden, 2000; Stjernholm et al., 2005). Such dispersal-reproduction trade-offs are well-documented in the context of migration in birds (Proctor and Lynch, 1998; Gill, 2006) and insects (Johnson, 1963; Rankin and Burchsted, 1992; Dingle, 1996), where development of reproductive organs is postponed until after migration.

Dispersal-reproduction trade-offs are also evident at smaller geographic scales of daily dispersal and foraging patterns (Van Dyck and Baguette, 2005; Bonte et al., 2012). In Trinidadian guppies, Poecilia reticulate, fast-start locomotor performance decreases with increased wet mass as pregnancy advances (Ghalambor et al., 2004). Gravid females of the side-blotched lizard (Uta stansburiana) display diminished locomotory endurance relative to post-gravid females (Miles et al., 2000), reproductive effort and locomotor performance are inversely correlated in the garter snake, Thamnophis sirtalis (Seigel et al., 1987), and carrying single-egg clutches significantly affect stamina and sprint speed in brown anole lizards, Anolis sagrei (Cox and Calsbeek, 2009). Small-scale movementreproduction trade-offs are well-documented in insects as well. By far the best-studied example is that of wing dimorphic morphs of insects (Harrison, 1980), in which wingless morphs typically invest more resources and invest them earlier into reproduction compared to winged morphs (Roff, 1986, 1990, 1994; Zera et al., 1999; Zera and Brink, 2000; Zera and Larsen, 2001). Flightless brachipterous male planthoppers, Prokelisia dolus, have a 3fold mating advantage over long-winged, macropterous males (Langellotto et al., 2000). In wing monomorphic species, weight loads associated with reproduction in the cabbage white butterfly, Pieris brassicae, impair flight performance (Almbro and Kullberg, 2012). Range expansion in response to global warming in the speckled wood butterfly, Pararge aegeria, has led to increased dispersal ability associated with reduced reproductive investment (Hughes et al., 2003). A recent review, however, showed that flight-fecundity tradeoffs in wing monomorphic insects may not be universal (Tigreros and Davidowitz, 2019). The tradeoff between dispersal and reproduction can be very sensitive, as seen in the grasshopper Stenobothrus lineatus, where mean egg laying was reduced by a rate of 0.36 eggs per day with each meter increase in mean daily dispersal radius (Samietz and Kohler, 2012). In the context of fragmentation-the focus of this paper-Gibbs and Van Dyck (2010) showed that females of the speckled wood butterfly from fragmented forest habitats that were forced to fly decreased investment into eggs, indicating the existence of a dispersal-reproduction trade-off. More importantly for the argument of this paper, they showed that butterflies from open, highly fragmented agricultural landscapes that were forced to fly did not suffer from reduced longevity as did butterflies from the unfragmented landscapes, suggesting that butterflies from fragmented landscapes were physiologically better able to cope with the increased dispersal demands relative to those from non-fragmented landscapes (Gibbs and Van Dyck, 2010).

\section{THE LANDSCAPE PHYSIOLOGY FRAMEWORK}

We present a novel framework that links physiological mechanism with landscape level processes to explain how fragmentation translates into population level persistence. Fragmentation increases the isolation among patches (amongpatch effect) and decreases patch size (within-patch effect) (Figure 1A). Patch size may also affect among-patch processes. However, its major effects relate to local population dynamics (Andren, 1994; Fahrig, 2003; Burkey and Reeds, 2006; Ewers and Didham, 2006). Patch size decreases with fragmentation, which results in a reduction in available resources in smaller 


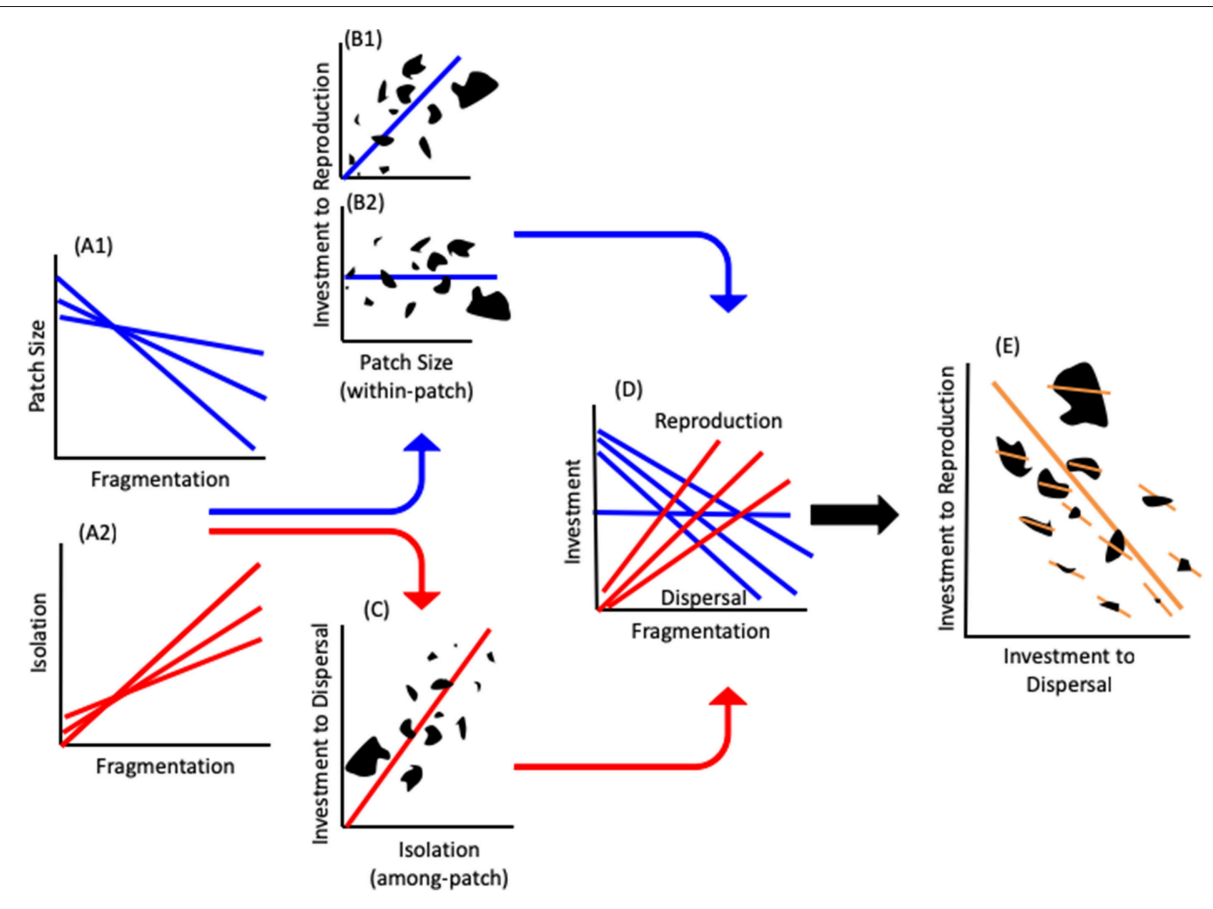

FIGURE 1 | The landscape physiology framework. The effects of fragmentation on patch size (A1) and isolation (A2). The effects of patch size on investment to reproduction. Individuals in larger patches will invest more into reproduction (B1) or, if the landscape is exactly at carrying capacity equilibrium (B2) investment into reproduction will not change with patch size. (C) The effect of among-patch isolation on resource allocation to dispersal with higher investment to dispersal increasing with the degree of isolation. (D) Resource investment to reproduction and dispersal along a fragmentation gradient. (E) Resource allocation tradeoff at the physiological level (short, within patch, lines) create the landscape-level tradeoff (long line). Note that the within-patch slopes are shallower in larger patches. The multiple lines in (A,D) indicate that the specific slope and intercept of the relationships will vary with different combinations of patches (B,C,E). The black shapes in $(\mathbf{B}, \mathbf{C}, \mathbf{E})$ represent patches of different shapes and sizes.

patches (MacArthur and Wilson, 1967; Rosenzweig, 1995). This may consequently lead to two possibilities regarding the percapita resource availability: (i) Constant per-capita resource availability, hence no change in density with area, due to the match between population size and resource quantity [e.g., Equilibrium theory (MacArthur and Wilson, 1967); and see empirical studies in Connor et al., 2000]. Consequently, investment to reproduction should stay constant with patch size (Figure 1B2 and horizontal line in Figure 1D); (ii) Increased percapita resource availability with area. Several reviews (Bowers and Matter, 1997; Bender et al., 1998; Debinski and Holt, 2000; Bowman et al., 2002) suggest that in almost half of studies, density has been shown to increase with a decrease in area, suggesting that individuals in larger areas may benefit from more per-capita resources. Therefore, reproductive investment should be higher in larger patches with more resources (Figure 1B1 and decreasing blue lines in Figure 1D) (Wheeler, 1996; Papaj, 2000), whereas increased among-patch isolation should lead to increased allocation to dispersal ability and hence greater investment in dispersal structures (Figure 1C) (Gibbs and Van Dyck, 2010; Bonte et al., 2012; Stevens et al., 2012). Consequently, as fragmentation increases, organismal investment into dispersal should increase, whereas investment into reproduction should decrease or remains equal (Figure 1D). Thus, both scenarios lead to a resource allocation trade-off between reproduction and dispersal along a fragmentation gradient (Figure 1E).

It is important to note that there are two slopes that reflect the physiological and landscape levels of organization (Figure 1E). The first is the among-individual-within-patch slopes determined by the physiological processes governing the resource allocation strategies of the individuals within a patch (Figure 1E). The second is the slope generated among patches within the landscape which incorporates the physiology into landscape level processes (Figure 1E). The slope and intercept of the within-patch tradeoff (the allocation strategy) is context dependent and will change with any combination of individuals within a patch and the environmental conditions they experience (Figures 1, 2). The among patch slope and position of each patch along it, is determined by the resource allocation strategies of the individuals within each patch. Thus, although we can make general predictions regarding the tradeoff within a landscape (Figure 2), the exact position of a given patch will be determined by the individuals and combination of patches measured (Figure 1).

We note that this framework is concerned with the tradeoff in the allocation of resources to dispersal vs. reproduction. We would expect the allocation of resources to these two traits to have cascading effects on the allocation of resources to other life 


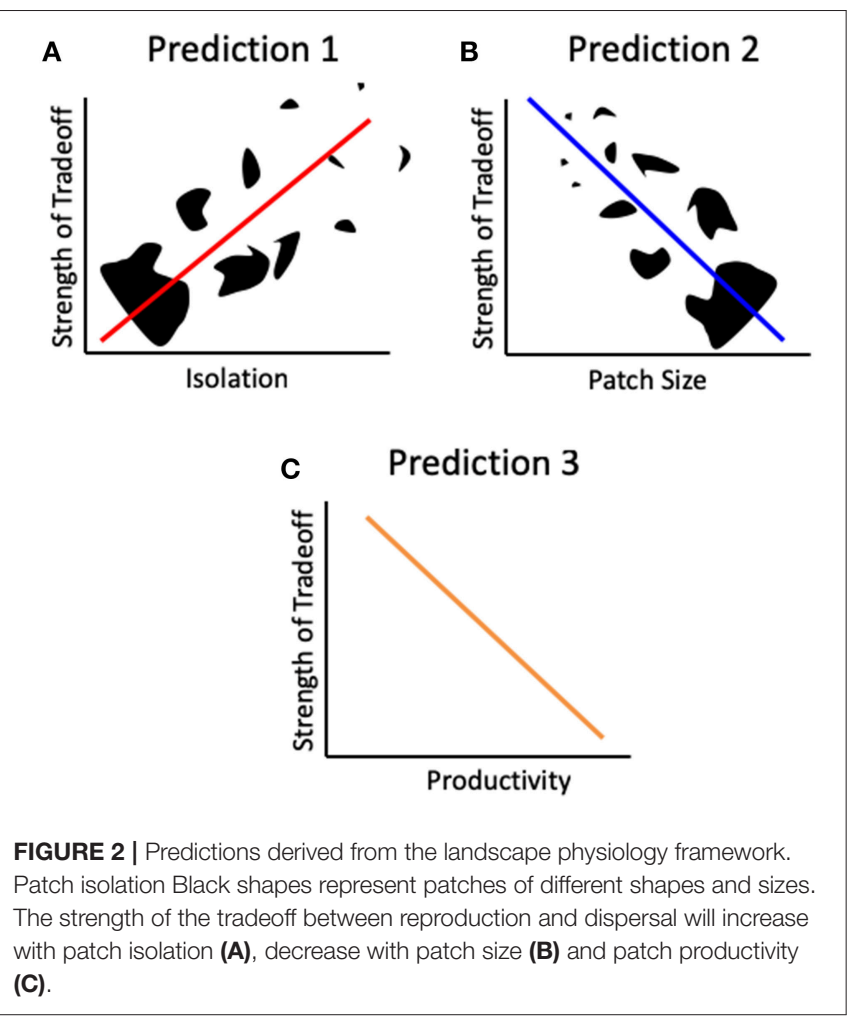

history traits as well. Such additional affects are beyond the scope of this paper.

\section{SPECIFIC HYPOTHESES}

The landscape physiology framework offers a number of hypotheses regarding the effect of fragmentation on the dispersal-reproduction trade-off. We assume that the effect of the environment on the dispersal-reproduction dynamics is expressed by the strength of the trade-off. The strength of a trade-off can be expressed as the negative slope of the regression between reproduction and dispersal (however these are measured) so that a steeper negative slope indicates a stronger trade-off (Figure 1E), or by the strength of the (genetic) correlation among the traits where a stronger trade-off is indicated by a stronger negative correlation (Zera and Harshman, 2001; Roff and Fairbairn, 2007; Boggs, 2009; King et al., 2011). The strength of a tradeoff can also be influenced by the amount of variation about the slope, such that a higher variance (a lower $R^{2}$ ) indicates a weaker tradeoff. For simplicity, in this paper, we only use the slope as a measure of the strength of the tradeoff.

We propose three specific hypotheses, which we are testing in our ongoing research, regarding the relationship between the effects of habitat fragmentation and the strength of the dispersalreproduction trade-off (Figure 2).

\section{Hypothesis 1}

Increased patch isolation leads to an increase in resource allocation to dispersal (Figures 1C,D). This hypothesis leads to the prediction of a positive relationship between the degree of isolation of a patch and the strength of the dispersal-reproduction trade-off, such that the trade-off will be stronger where isolation is higher (Figure 2A). This prediction will result in lower reproductive rates in the more isolated patches.

\section{Hypothesis 2}

Increased patch size leads to either a constant or an increase in resource allocation to reproduction (Figures 1B1,D). This hypothesis leads to the prediction of a negative relationship between patch size and the strength of the dispersal-reproduction trade-off, such that smaller patches will exhibit a stronger tradeoff (Figure 2B). This prediction will result in lower reproductive rates in the smaller patches.

\section{Hypothesis 3}

An increase in patch productivity will provide enough resources for both dispersal and reproduction. This hypothesis leads to the prediction that the strength of the trade-off will decrease with increased productivity, i.e., in patches with higher resource availability (Figure 2C). This will result in lower reproductive rates in fragmented habitats of low productivity. This is supported by what is known of insect reproductive physiology: reproductive output is a function of the amount of resources acquired (Wheeler, 1996; Papaj, 2000). Resource abundance can affect the strength of a trade-off: it can be eliminated when resources are plentiful, or exacerbated when resources are limited, as described above.

Under landscape fragmentation, Hypotheses 1 and 2 are not independent, as more fragmented areas are more isolated and have smaller patches. Hypotheses 2 and 3 propose the same pattern, but in different spatial configurations: one along a fragmentation gradient (i.e., change in patch size) and the other along a productivity gradient. A landscape that includes both gradients, varying independently, will serve as an ideal model system to test the proposed hypotheses, as it can provide evidence that the shared mechanism works regardless of the spatial configuration and allows effects due to fragmentation to be separated from effects due to productivity.

\section{STUDY SYSTEM}

The appropriate study system in which to test how the dispersalreproduction trade-off translates landscape fragmentation into population-level processes must fulfill the following criteria. First, fragments must be well-defined. Second, the fragmentation gradient must occur over a small enough area as to minimize abiotic variation from weather or other factors. Third, the gradient must have existed over sufficient evolutionary time to allow evolutionary responses in the dispersal-reproduction tradeoff to emerge. Fourth, the study organism must be in high enough abundance to allow population-level effects to be measured. Finally, the fragmentation gradient must be at an appropriate grain for the organism's life-history (Baguette and van Dyck, 2007); the organism should be mobile enough so that dispersal is an important component of its life-history, but not so mobile that it can easily emigrate from the gradient. 
Our current consideration and specific examples relate to terrestrial environments due to our own research interests. However, our framework should be relevant to any other environment where individuals face energy constraints and must allocate their resources to either fecundity or movement to another habitat patch. For example, in marine environments, isolated coral reefs are distributed at different distances and have different habitat quality (e.g., Belmaker et al., 2007, 2009). Dispersal among different coral reefs (Belmaker et al., 2011) is costly for individuals due the open-sea hostile environment, but may allow the new arrivals to have reduced predation pressure (Belmaker et al., 2005) and possibly an increase in fitness. Consequently, we expect that the dispersal strategies of individuals that are based on the heterogeneity of the coral reef system, will result in higher fitness and their fecundity-vs.movement strategy will be favored by natural selection.

Although we present our framework and hypotheses in the context of fragmentation gradients, there is no reason this framework cannot be extended to other gradients of environmental variation. This means, that this framework is applicable to any natural situation where organisms have to prioritize between investment in dispersal and investment in fecundity to maximize their fitness. Given that in natural systems patch size and distance are not necessarily negatively correlated as they are along a fragmentation gradient, one can test the proposed framework in clusters of close habitat patches of different sizes or in clusters of similar sized patches of different distances. This allows for separate tests of hypotheses 1 and 2 independently. Such studies can be applied to different landscapes and taxa.

\section{SUMMARY}

The framework proposed here integrates two disparate fields, landscape ecology and evolutionary physiology, promoting the emerging new field of Landscape Physiology (Chown et al., 2004; Chown and Gaston, 2008; Bonte et al., 2012; Ellis et al., 2012). Landscape ecology relies on correlations between landscape and population/community parameters but usually ignores individual-level mechanisms. Evolutionary physiology, in contrast, is a mechanistic discipline that focuses on the microhabitat and often ignores landscape-level processes. This

\section{REFERENCES}

Aguette, M., and Schtickzelle, N. (2006). Negative relationship between dispersal distance and demography in butterfly metapopulations. Ecology 87, 648-654. doi: $10.1890 / 04-1631$

Almbro, M., and Kullberg, C. (2012). Weight loading and reproductive status affect the flight performance of pieris napi butterflies. J. Insect Behav. 25, 441-452. doi: 10.1007/s10905-011-9309-1

Andren, H. (1994). Effects of habitat fragmentation on birds and mammals in landscapes with different proportions of suitable habitat: a review. Oikos 71, 355-366 doi: 10.2307/3545823

Baguette, M., and van Dyck, H. (2007). Lamdscape connectivity and animal behavior: functional grain as a key determinant for dispersal. Landscape Ecol. 22, 1117-1129. doi: 10.1007/s10980-007-9108-4 framework generates explicit and testable hypotheses of how an organism translates habitat characteristics resulting from fragmentation, through the physiological mechanism of resource allocation strategies, into population dynamic parameters of reproduction, survival, and abundance. This framework allows us to quantify and integrate both characteristics of habitat fragmentation and the dispersal-reproduction trade-off to produce response functions that can be used in inferring population persistence. All components of this framework are already well-supported in the literature of the respective fields: (a) habitat fragmentation reduces patch size and increases isolation, reducing species abundances and population persistence; (b) organisms in isolated, marginal, or fragmented habitats invest more in dispersal; and (c) dispersal-reproduction trade-offs are generally common. Previous studies have looked at qualitative differences among habitats (e.g., fragmented or not, (Gibbs and Van Dyck, 2010); or old or new populations, Hanski et al., 2006; Hanski, 2011). This framework extends beyond such studies in that it allows for the quantification of habitat characteristics and allocation strategies, such that we can determine the relationships between them to test explicit ecological and physiological predictions of resource allocation and life history strategies. Integrating across physiology and the landscape in one unified framework will extend our ability to understand population extinction and persistence in light of current increases in habitat loss and climate change.

\section{AUTHOR CONTRIBUTIONS}

YZ and GD contributed equally to the development of ideas and writing of the manuscript.

\section{FUNDING}

This study was supported by NSF grants IOS-1656279 and IOS1053318 to GD and BSF grant 2016604 to YZ.

\section{ACKNOWLEDGMENTS}

We thank Judie Bronstein, Burt Kotler, Natasha Tigreros, Giorgi Kozhoridze, Julie Messier, and three reviewers for comments on previous versions of the manuscript.
Bakker, J., van Rijswijk, M. E. C., Weissing, F. J., and Bijlsma, R. (2010). Consequences of fragmentation for the ability to adapt to novel environments in experimental Drosophila metapopulations. Conserv. Genet. 11, 435-448 doi: 10.1007/s10592-010-0052-5

Belanger, L., and Grenier, M. (2002). Agriculture intensification and forest fragmentation in the St. Lawrence valley, Québec, Canada. Landsc. Ecol. 17, 495-507. doi: 10.1023/A:10214439 29548

Belmaker, J., Ben-Moshe, N., Ziv, Y., and Shashar, N. (2007). Determinants of the steep species-area relationship of coral reef fishes. Coral Reefs 26, 103-112. doi: 10.1007/s00338-006-0162-1

Belmaker, J., Shashar, N., and Ziv, Y. (2005). Effects of small-scale isolation and predation on fish diversity on experimental reefs. Mar. Ecol. Prog. Ser. 289, 273-283. doi: 10.3354/meps289273 
Belmaker, J., Ziv, Y., and Shashar, N. (2009). Habitat patchiness and predation modify the distribution of coral-dwelling damfish. Mar. Biol. 156, 447-454. doi: 10.1007/s00227-008-1098-5

Belmaker, J., Ziv, Y., and Shashar, N. (2011). The influence of connectivity on richness and temporal variation of reef fishes. Landsc. Ecol. 26, 587-597. doi: 10.1007/s10980-011-9588-0

Bender, D. J., Contreras, T. A., and Fahrig, L. (1998). Habitat loss and population decline: a meta-analysis of the patch size effect. Ecology 79, 517-533. doi: 10. 1890/0012-9658(1998)079[0517:HLAPDA]2.0.CO;2

Berwaerts, K., Van Dyck, H., Van Dongen, S., and Matthysen, E. (1997). Morphological and genetic variation in the speckled wood Butterfly (Pararge Aegeria L.) among differently fragmented landscapes. Netherlands J. Zool. 48, 241-253. doi: 10.1163/156854298X00093

Boggs, C. L. (2009). Understanding insect life histories and senescence through a resource allocation lens. Funct. Ecol. 23, 27-37. doi: $10.1111 / j .1365-2435.2009 .01527 . x$

Bonte, D., Van Dyck, H., Bullock, J., M., Coulon, A., Delgado, M., Gibbs, M., et al., (2012). Costs of dispersal. Biol. Rev. 87, 290-312. doi: 10.1111/j.1469-185X.2011.00201.x

Bowers, M. A., and Matter, S. F. (1997). Landscape ecology of mammals: relationships between density and patch-size. J. Mammal. 78, 999-1013. doi: $10.2307 / 1383044$

Bowman, J., Cappuccino, N., and Fahrig, L. (2002). Patch size and population density: the effect of immigration behavior. Conserv. Ecol. 6:9. doi: 10.5751/ES-00354-060109

Brown, J. H., and Kodric-Brown, A. (1977). Turnover rates in insular biogeography: effect of immigration on extinction. Ecology 58, 445-449. doi: $10.2307 / 1935620$

Burkey, T. V., and Reeds, D. H. (2006). The effects of habitat fragmentation on extinction risk: mechanisms and synthesis. Songklanakarin J. Sci. Technol. 28, 9-37.

Chippindale, A. K., Leroi, A. M., Kim, S. B., and Rose, M. R. (1993). Phenotypic plasticity and selection in Drosophila life-history evolution. Nutrition, I., and the cost of reproduction. J. Evol. Biol. 6, 171-193. doi: 10.1046/j.1420-9101.1993.6020171.x

Chown, S. L., and Gaston, K. J. (2008). Macrophysiology for a changing world. Proc. R. Soc. B 275, 1469-1478. doi: 10.1098/rspb.2008.0137

Chown, S. L., Gaston, K. J., and Robinson, D. (2004). Macrophysiology: large-scale patterns in physiological traits and their ecological implications. Funct. Ecol. 18, 159-167. doi: 10.1111/j.0269-8463.2004.00825.x

Connor, E. F., Courtney, A. C., and Yoder, J. M. (2000). Individuals-area relationships: the relationship between animal population density and area. Ecology 81, 734-748. doi: 10.1890/0012-9658(2000)081[0734:IARTRB]2.0. $\mathrm{CO} ; 2$

Cox, R. M., and Calsbeek, R. (2009). Severe costs of reproduction persist in anolis lizards despite the evolution of a single-egg clutch. Evolution 64, 1321-1330. doi: $10.1111 / j .1558-5646.2009 .00906 . x$

Davidowitz, G. (2016). Endocrine proxies can simplify endocrine complexity to enable evolutionary prediction. Integr. Compar. Biol. 56, 198-206. doi: $10.1093 /$ icb/icw021

Davidowitz, G., Roff, D. A., and Nijhout, H. F. (2016). Synergism and antagonism of proximate mechanisms enable and constrain the response to simultaneous selection on body size and development time: an empirical test using experimental evolution. Am. Natural. 188, 499-520. doi: 10.1086/688653

de jong, G. (1993). Covariances between traits deriving from successive allocations of a resource. Funct. Ecol. 7, 75-83. doi: 10.2307/2389869

Debinski, D. M., and Holt, R. D. (2000). A survey and overview of habitat fragmentation experiments. Conserv. Biol. 14, 342-355. doi: 10.1046/j.1523-1739.2000.98081.x

Dingle, H. (1996). Migration: The Biology of Life on the Move. New York, NY: Oxford University Press.

Ellis, R. D., McWhorter, T. J., and Maron, M. (2012). Integrating landscape ecology and conservation physiology. Landsc. Ecol. 27, 1-12. doi: 10.1007/s10980-011-9671-6

Ewers, R. M., and Didham, R. K. (2006). Confounding factors in the detection of species responses to habitat fragmentation. Biol. Rev. 81, 117-142. doi: $10.1017 /$ S1464793105006949
Fahrig, L. (2002). Effect of habitat fragmentation on the extinction threshold: a synthesis. Ecol. Appl. 12, 346-353. doi: 10.2307/3060946

Fahrig, L. (2003). Effects of habitat fragmentation on biodiversity. Annu. Rev. Ecol. Syst. 34, 487-515. doi: 10.1146/annurev.ecolsys.34.011802.132419

Feder, M. E., Bennet, A. F., and Huey, R. B. (2000). Evolutionary physiology. Annu. Rev. Ecol. Syst. 31, 315-341. doi: 10.1146/annurev.ecolsys.31.1.315

Flatt, T., and Heyland, A. (2011). Mechanisms of Life History Evolution: The Genetics and Physiology of Life History Traits and Trade-offs. Oxford: Oxford University Press.

Garland, T., and Carter, P. A. (1994). Evolutionary physiology. Annu. Rev. Physiol. 56, 579-621. doi: 10.1146/annurev.ph.56.030194.003051

Gavish, Y., Ziv, Y., and Rosenzweig, M. L. (2012). Decoupling fragmentation from habitat lost: the effect of fragmentation on biodiversity in a patchy agroecosystem. Conserv. Biol. 26, 150-159. doi: 10.1111/j.1523-1739.2011.01799.x

Ghalambor, C. K., Reznick, D. N., and Walker, J. A. (2004). Constraints on adaptive evolution: the functional trade-off between reproduction and fast-start swimming performance in the trinidadian guppy (Poecilia reticulata). Am. Nat. 164, 38-50. doi: 10.1086/421412

Gibbs, M., and Van Dyck, H. (2010). Butterfly flight activity affects reproductive performance and longevity relative to landscape structure. Oecologia 163, 341-350. doi: 10.1007/s00442-010-1613-5

Giladi, I., Ziv, Y., May, F., and Jeltsch, F. (2011). Scale-dependent determinants of plant species density in a semiarid fragmented agroecosystem. J. Veg. Sci. 22, 983-996. doi: 10.1111/j.1654-1103.2011.01309.x

Gill, F. B. (2006). Ornithology. New York, NY: W.H. Freeman.

Gokhale, R. H., and Shingleton, A. W. (2015). Size control: the developmental physiology of body and organ size regulation. WIREs Dev. Biol. 4, 335-356. doi: $10.1002 /$ wdev. 181

Green, R. E., Cornell, S. J., Scharlemann, J. P., and Balmford, W. A. (2005). Farming and the fate of wild nature. Science 307, 550-555. doi: 10.1126/science.1106049

Guerra, P. A. (2011). Evaluating the life-history trade-off between dispersal capability and reproduction in wing dimorphic insects: a meta-analysis. Biol. Rev. 86, 813-835. doi: 10.1111/j.1469-185X.2010.00172.x

Hanfling, B., Durka, W., and Brandl, R. (2004). Impact of habitat fragmentation on genetic population structure of roach, Rutilus rutilus, in a riparian ecosystem. Conserv. Genet. 5, 247-257. doi: 10.1023/B:COGE.0000030008.20492.2c

Hanski, I. (2011). Eco-evolutionary spatial dynamics in the Glanville fritillary butterfly. Proc. Natl. Acad. Sci. U.S.A. 108, 14397-14404. doi: 10.1073/pnas.1110020108

Hanski, I., and Gaggiotto, O. E. (2004). Ecology, Genetics, and Evolution of Metapopulations. Burlington: Elsevier Academic Press.

Hanski, I., and Gilpin, M. E. (eds.). (1997). Metapopulation Biology: Ecology, Genetics and Evolution. San Diego: Academic Press.

Hanski, I., Saastamoinen, M., and Ovaskainen, O. (2006). Dispersal-related life history trade offs in a butterfly metapopulation. J. Anim. Ecol. 75, 91-100. doi: 10.1111/j.1365-2656.2005.01024.x

Hanski, I., Zurita, G. A., Bellocq, M. I., and Rybicki, J. (2013). Speciesfragmented area relationship. Proc. Natl. Acad. Sci. U.S.A. 110, 12715-12720. doi: $10.1073 /$ pnas.1311491110

Harrison, R. G. (1980). Dispersal polymorphisms in insects. Ann. Rev. Ecol Syst. $11,95-118$

Harshman, L. G., and Zera, A. J. (2007). The cost of reproduction: the devil in the details. Trends Ecol. Evol. 22, 80-86. doi: 10.1016/j.tree.2006. 10.008

Hughes, C. L., Hill, J. K., and Dytham, C. (2003). Evolutionary trade-offs between reproduction and dispersal in populations at expanding range boundaries. Proc. R. Soc. B. 270, S147-S150. doi: 10.1098/rsbl.2003.0049

Johnson, C. G. (1963). Physiological factors in insect migration by flight. Nature 198, 423-427. doi: 10.1038/198423a0

Kaitala, A. (1987). Dynamic life-history strategy of the waterstrider gerristhoracicus as an adaptation to food and habitat variation. Oikos 48, 125-131. doi: $10.2307 / 3565848$

Karasov, W. H., and Martinez del Rio, C. (2007). Physiological Ecology: How Animals Process Energy, Nutrients, and Toxins. Princeton, NJ: Princeton University Press.

Karieva, P. M., Kingsolver, J. G., and Huey, R. B. (1992). Biotic Interaction and Global Change. Sunderland, MA: Sinauer Associates, Inc. 
King, E. G., Fairbairn, D. J., and Roff, D. A. (2011). Extracting the underlying physiological determinants of resource-based trade-offs: a principal components approach. Am. Nat. 180, 394-402. doi: 10.1086/667194

Klapwijk, M. J., and Lewis, O. T. (2001). "Effects of climate change and habitat fragmentation on trophic interactions," in Encyclopedia of Life Support Systems," in Tropical Biology and Conservation Management, eds. K. Del Claro, P. S.Oliveira, and V. Rico-Gray (Oxford: Eolss Publishers Co Ltd), 26-33.

Langellotto, G. A., Denno, R. F., and Ott, J. R. (2000). A trade-off between flight capability and reproduction in males of a wing-dimorphic insect. Ecology 81, 865-875. doi: 10.1890/0012-9658(2000)0810865:ATOBFC2.0.CO;2

MacArthur, R. H., and Wilson, E. O. (1967). The Theory of Island Biogeography. Princeton, NJ: Princeton University Press.

Marden, J. H. (2000). Variability in the size, composition, and function of insect flight muscle. Annu. Rev. Physiol. 62, 157-178. doi: 10.1146/annurev.physiol.62.1.157

Miles, D. B., Sinerveo, B., and Frankino, W. A. (2000). Reproductive burden, locomotor performance, and the cost of reproduction in free ranging lizards. Evolution 54, 1386-1395. doi: 10.1111/j.0014-3820.2000.tb00570.x

Millennium Ecosystem Assessment (2005). Ecosystems and Human Well-Being: Current State and Trends. Washington, DC: Island Press.

Nijhout, H. F., and Emlen, D. J. (1998). Competition among body parts in the development and evolution of insect morphology. Proc. Natl. Acad. Sci. U.S.A. 95, 3685-3689. doi: 10.1073/pnas.95.7.3685

Nijhout, H. F., Riddiford, L. M., Mirth, C., Shingleton, A. W., Suzuki, Y., and Callier, V. (2013). The developmental control of size in insects. WIREs Dev. Biol. 3, 113-134 doi: 10.1002/wdev.124

Opdam, P., and Wascher, D. (2004). Climate change meets habitat fragmentation: linking landscape and biogeographical scale levels in research and conservation. Biol. Conserv. 117, 285-297. doi: 10.1016/j.biocon.2003.12.008

Papaj, D. R. (2000). Ovarian dynamics and host use. Annu. Rev. Entomol. 45, 423-448. doi: 10.1146/annurev.ento.45.1.423

Perrin, N., Bradley, M. C., and Calow, P. (1990). Plasticity of storage-allocation in daphnia magna. Oikos 59, 70-74. doi: 10.2307/3545124

Proctor, N. S., and Lynch, P. J. (1998). Manual of Ornithology: Avian Structure and Function. New Haven, CT: Yale University Press.

Rankin, M. A., and Burchsted, J. C. A. (1992). The cost of migration in insects. Annu. Rev. Entomol. 37, 533-559. doi: 10.1146/annurev.en.37.010192. 002533

Reed, D. H. (2004). Extinction risk in fragmented habitats. Anim. Conserv. 7, 181-191. doi: 10.1017/S1367943004001313

Ricklefs, R. E., and Wikelski, M. (2002). The physiology/life history nexus. Trends Ecol. Evol. 17, 462-468. doi: 10.1016/S0169-5347(02)02578-8

Roff, D. A. (1986). The evolution of wing dimorphism in insects. Evolution 40, 1009-1020. doi: 10.1111/j.1558-5646.1986.tb00568.x

Roff, D. A. (1990). Selection for Changes in the incidence of wing dimorphism in gryllus-firmus. Heredity 65, 163-168. doi: 10.1038/hdy.1990.84

Roff, D. A. (1992). The Evolution of Life Histories. New York, NY: Chapman and Hall.

Roff, D. A. (1994). Habitat persistence and the evolution of wing dimorphism in insects. Am. Nat. 144, 772-798. doi: 10.1086/285706

Roff, D. A., and Fairbairn, D. J. (2007). Laboratory evolution of the migratory polymorphism in the sand cricket: combining physiology with quantitative genetics. Phys. Biochem. Zool. 80, 358-369. doi: 10.1086/ 518012

Rogowitz, G. L. (1996). Trade-offs in energy allocation during lactation. Am. Zool. 36, 197-204. doi: 10.1093/icb/36.2.197

Rosenzweig, M. L. (1995). Species Diversity in Space and Time. Cambridge: Cambridge University Press.
Samietz, J., and Kohler, G. (2012). A fecundity cost of (walking) mobility in an insect. Ecol. Evol. 2, 2788-2793. doi: 10.1002/ece3.396

Seigel, R. A., Huggins, M. M., and Ford, N. B. (1987). Reduction in locomotor ability as a cost of reproduction in gravid snakes. Oecologia 73, 481-485. doi: $10.1007 / \mathrm{BF} 00379404$

Stearns, S. C. (1989). Trade-offs in life history evolution. Funct. Ecol. 3, 259-268. doi: $10.2307 / 2389364$

Stearns, S. C. (1992). The Evolution of Life Histories. Oxford: Oxford University Press.

Stevens, V. M., Trochet, A., Van Dyck, H., Clobert, J., and Baguette, M. (2012). How is dispersal integrated in life histories: a quantitative analysis using butterflies. Ecol. Lett. 15, 74-86. doi: 10.1111/j.1461-0248.2011.01709.x

Stjernholm, F., Karlsson, B., and Boggs, C. L. (2005). Age-related changes in thoracic mass: possible reallocation of resources to reproduction in butterflies. Biol. J. Linnean Soc. 86, 363-380. doi: 10.1111/j.1095-8312.2005.00542.x

Templeton, A. R., Robertson, R. J., Brisson, J., and Strasburg, J. (2001). Disrupting evolutionary processes: the effect of habitat fragmentation on collared lizards in the Missouri Ozarks. Proc. Natl. Acad. Sci. U.S.A. 10, 5426-5432. doi: 10.1073/pnas.091093098

Tigreros, N., and Davidowitz, G. (2019). Flight-fecundity tradeoffs in wingmonomorphic insects. Adv. Insect Physiol. doi: 10.1016/bs.aiip.2019.02.001. [Epub ahead of print].

Van Dyck, H., and Baguette, M. (2005). Dispersal behaviour in fragmented landscapes: routine or special movements? Basic Appl. Ecol. 6, 535-545. doi: 10.1016/j.baae.2005.03.005

Wheeler, D. (1996). The role of nourishment in oogenesis. Annu. Rev. Entomol. 41, 407-431. doi: 10.1146/annurev.en.41.010196.002203

Willi, Y., and Hoffmann, A. A. (2012). Microgeographic adaptation linked to forest fragmentation and habitat quality in the tropical fruit fly Drosophila birchii. Oikos 121, 1627-1637. doi: 10.1111/j.1600-0706.2011. 20156.x

Zera, A. J., and Brink, T. (2000). Nutrient absorption and utilization by wing and flight muscle morphs of the cricket Gryllus firmus: implications for the trade-off between flight capability and early reproduction. J. Insect Physiol. 46, 1207-1218. doi: 10.1016/S0022-1910(00)00041-X

Zera, A. J., and Harshman, L. G. (2001). The physiology of life history trade-offs in animals. Annu. Rev. Ecol. Syst. 32, 95-126. doi: 10.1146/annurev.ecolsys.32.081501.114006

Zera, A. J., and Larsen, A. (2001). The metabolic basis of life history variation: genetic and phenotypic differences in lipid reserves among life history morphs of the wing-polymorphic cricket, Gryllus firmus. J. Insect Physiol. 47, 1147-1160. doi: 10.1016/S0022-1910(01)00096-8

Zera, A. J., Sall, J., and Otto, K. (1999). Biochemical aspects of flight and flightlessness in Gryllus: flight fuels, enzyme activities and electrophoretic profiles of flight muscles from flight-capable and flightless morphs. J. Insect Physiol. 45, 275-285. doi: 10.1016/S0022-1910(98) 00123-1

Conflict of Interest Statement: The authors declare that the research was conducted in the absence of any commercial or financial relationships that could be construed as a potential conflict of interest.

Copyright (c) 2019 Ziv and Davidowitz. This is an open-access article distributed under the terms of the Creative Commons Attribution License (CC BY). The use, distribution or reproduction in other forums is permitted, provided the original author(s) and the copyright owner(s) are credited and that the original publication in this journal is cited, in accordance with accepted academic practice. No use, distribution or reproduction is permitted which does not comply with these terms. 